\title{
Application of Fundamental Mathematical Structure using a Self Game for Cognitive Development in Children
}

\author{
K. Suneetha Devi \\ PG Mathematics, Acharya Nagarjuna University, Guntur, Andhra Pradesh, India
}

\begin{abstract}
How to cite this paper: K. Suneetha Devi "Application of Fundamental Mathematical Structure using a Self Game for Cognitive Development in Children" Published in International Journal of Trend in Scientific Research and Development (ijtsrd), ISSN: 24566470, Volume-3 | Issue-3 , April 2019, pp.843-846, URL: https://www.ijtsrd.c om/papers/ijtsrd23 121.pdf

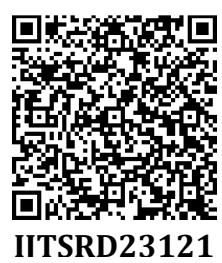

Copyright (C) 2019 by author(s) and International Journal of Trend in Scientific Research and Development Journal. This is an Open Access article distributed under

the terms of the Creative Commons

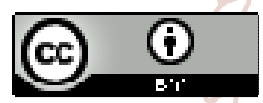
Attribution License (CC BY 4.0) (http://creativecommons.org/licenses/ by/4.0)

\section{INTRODUCTION}

In ancient days games played for fun consisted application of mathematical concepts which turned out to be their primary source of learning at a tender age. (No wonder, Indians contributed to Mathematics by recording the distances between the heavenly objects/ discovering, zero ages before the rest of the world)

The Set of positive whole Numbers 1,2,3,4,5,6,7,8,9 and so on which are usually called the set of natural numbers; relationships between different sorts of numbers with basic four fundamental (addition, subtraction, multiplication, division) structures are explained in this play way method.

Piaget's 2nd Preoperational stage \& 3rd Concrete operational stage of cognitive development is directly applied in this self-play game method.

Cognitive development of children involves playing \&learning skills, better control over attention, memory \&thinking, problem solving skills, logical thinking, letting children assess their own ability to reason out task and find out solution. These skills progress from Piaget's theory of 3rd stage concrete thinking.

\section{PROCEDURE}

The object of the "Snake \& Ladder play way method" is to navigate the game piece, according to the roll of the dice. The dice are small objects meant to be rolled (usually played with 1 cubes), that can rest in multiple positions, used for generating random numbers from 1 to 6 through combination. The set of positive whole numbers are written ranging from 1-100 numbers. The Game starts at the bottom left circle and finishes at the top left triangle, helped or hindered by ladder and snakes. The four basic mathematical fundamental (addition, subtraction, multiplication, division), are indicated in rectangle shapes. With this "Snake \& Ladder" self-game method we explain children about twenty fundamental concepts in core Mathematics right in primary education system.

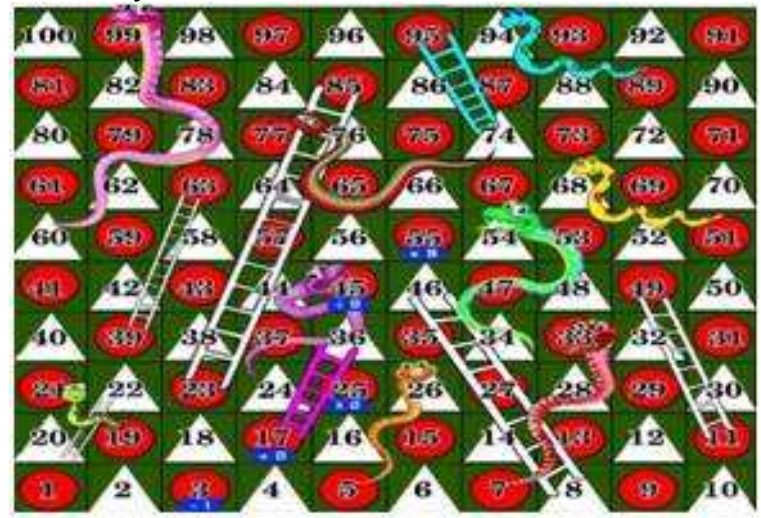

Figure 1 


\section{Concept: 1}

Single, Double \& Triple digits: Children can identify \& learn single- \& Double-digits numbers.

Ex: $1,2,22,33,44,666,759$, etc.

\section{Concept: 2}

Even Numbers: Identify the even numbers that are exactly divisible by 2 . We can teach up to 50 even numbers. All even numbers are located at red/white triangle.

Ex: $2,4,8,12$
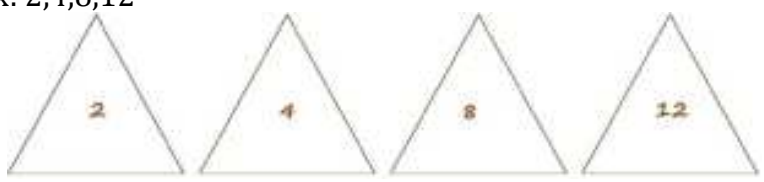

\section{Concept: 3}

Odd Numbers: Odd numbers which are no exactly divisible by 2 . An easy way to tell whether a number is odd is to look at its final digit. If the number ends with an odd digit, then the number as a whole is an odd one. We can teach up to 50 odd numbers. It is easy to identity all odd number located in red circles.

\section{Ex:1,3,5,7,9}
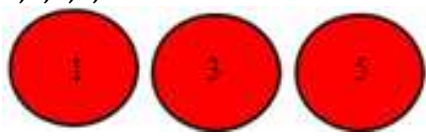

Figure 3
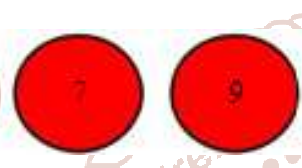

Concept: 4
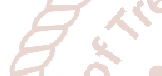

Figure 2

\section{Concept: 6}

Greater than: In typical mathematical usage, the greaterthan sign is typically placed between the two values being compared and signals that the first number is greater than the second number.

Ex: $76>75$

\section{Concept: 7}

Less than: When one value is smaller than another, we use a "less than" sign. Ex: $65<66$

\section{Concept: 8}

Before, after \& between Numbers: Counting before, after and between numbers up to 100 improves the child's counting skills. Number counting is a basic math skill that will help children to recognize the order of the numbers.

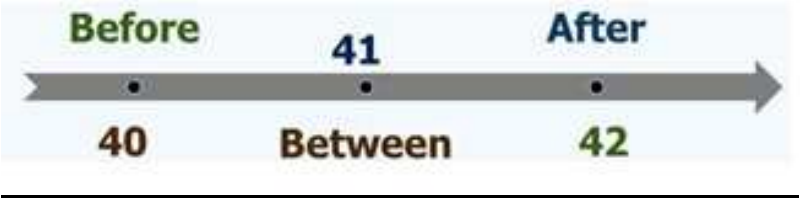

Figure 6

Concept: 9

The smallest one-digit number is 1 (one) and greatest onedigit number is 9 .

There are 90 numbers of two digits. The smallest two-digit number is 10 and greatest two-digit number is 99 .

Ascending Order: Children can learn ascending order when numbers are arranged from the smallest to the largest numbers.

Ex: 1, 12, 25, 39, 50 etc.

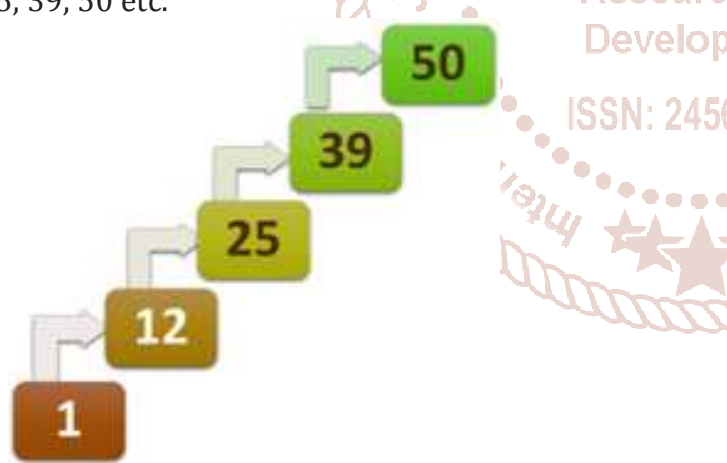

Figure 4

Concept: 5

Descending Order: Children can learn descending order when numbers are arranged from the largest to the smallest number.

Ex: 60, 32, 21, 10, 2 etc.

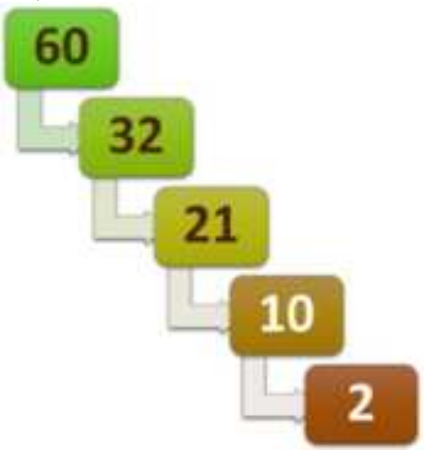

Figure 5

\section{Concept: 10}

Estimation of a number: Estimation of a number is to find the nearest whole number means looking at the digit to the right of the original digit considered. Ex: Which number is near to the 50 ? 46 or 51 ?a) 51

\section{Concept: 11}

Multiplication: Mathematical operation performed on a pair of numbers in order to derive a third number called a product. For positive integers, multiplication consists of adding a number (the multiplicant) to itself - specified number of times. From Snake Ladder Game we can explain a child all 1-9 multiplication tables. Ex: Multiplies of 2 or 2, 4, 6, 8, 10

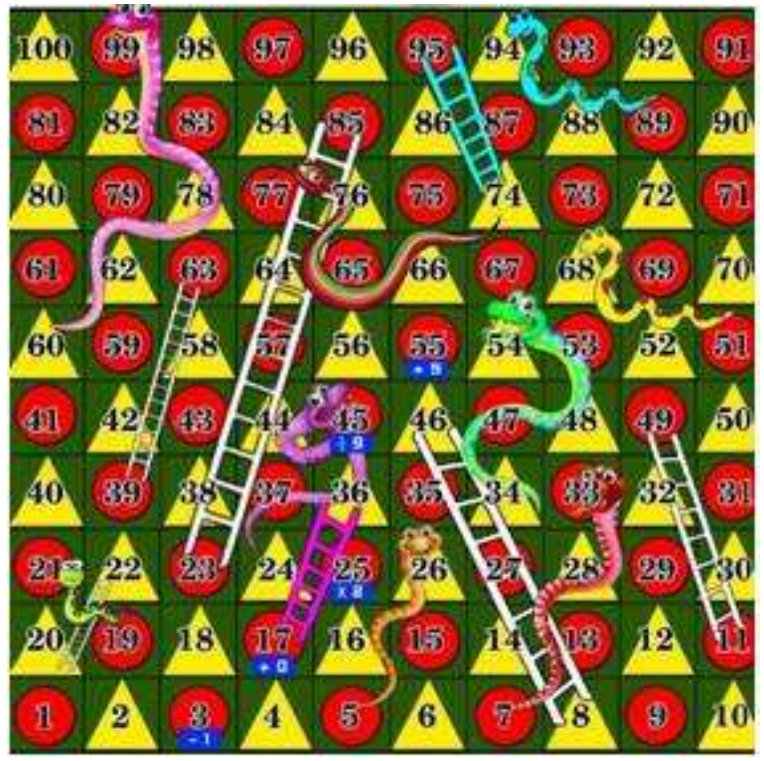

Figure 7 


\section{Concept: 12}

Children can calculate the: How many times? Concept. Ex: 2 times of 2 is 4 .

4 times of 2 is 8 .

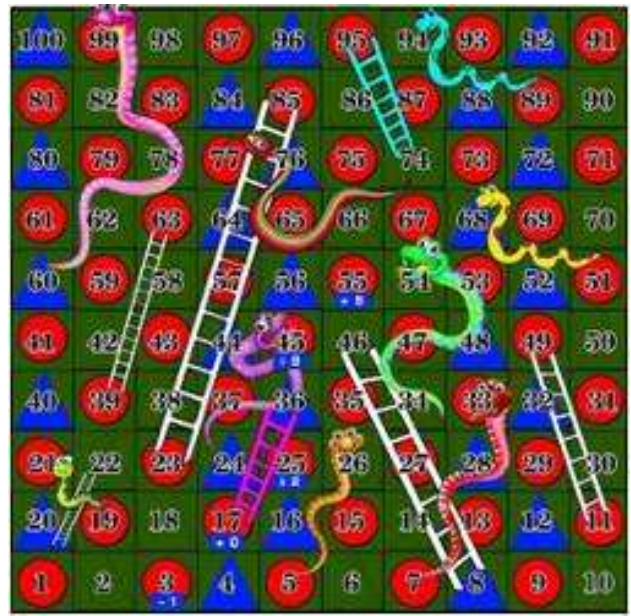

Figure 8

\section{Concept: 15}

If a player rolls the dice and reached position 25 , as the result of the action supposed to be taken is multiplication, $25^{*} 2=50$, he can move his piece to the position 50 .

Ex: $25 \mathrm{X} 2=50$

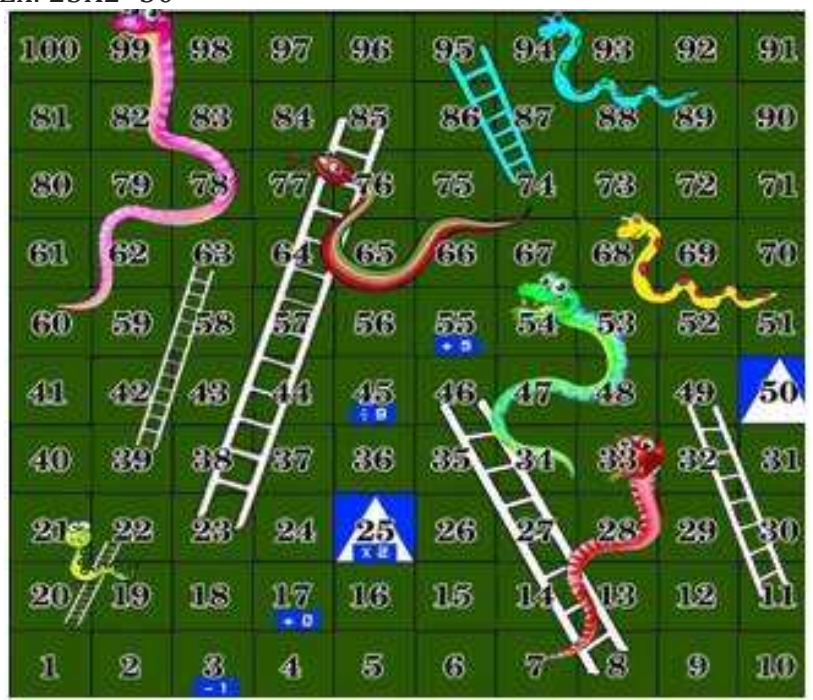

Concept: 13

When the student rolls the dice if the number 2 is on the Dice, child moves his/her piece to the position 2 , if the next roll of dice shows 3 then the student adds up 3 to the current position on the board and moves the piece to be placed at the number 5. Addition concept is thus repeated throughout. Ex: $55+5=60$.

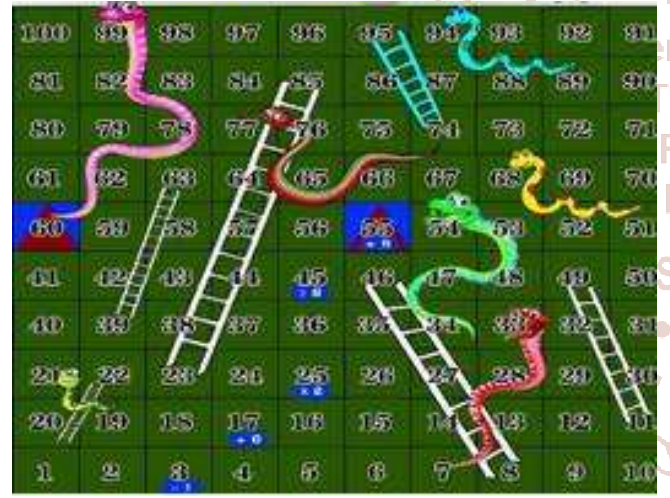

Figure 9

\section{Concept: 14}

If a player rolls the dice that has an outcome of number 3 , and if the action to be taken in the position 3 on the board game is -1 then, in 3-1 applying the basic subtraction, the player needs to move his piece to position 2. Ex: 3-1=2

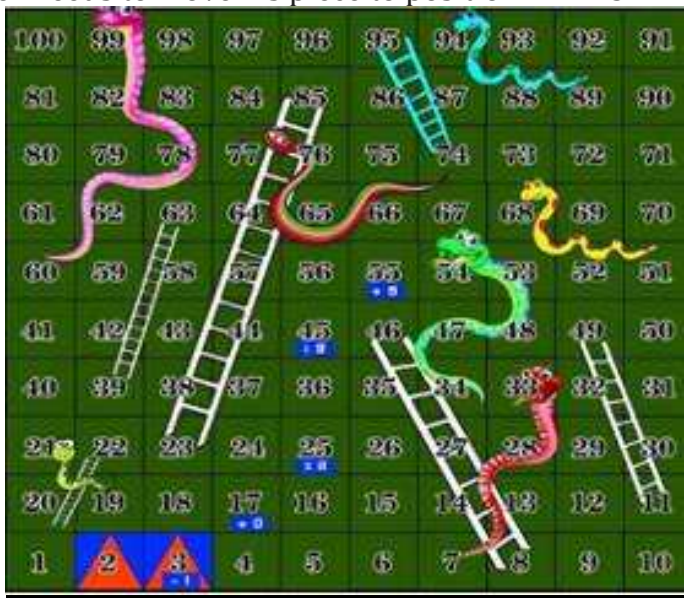

Figure 10

\section{Concept: 16}

If the player reached position 45 , as the division action is expected to be taken as per the board, $45 / 9$, then the student immediately goes to position 5 .

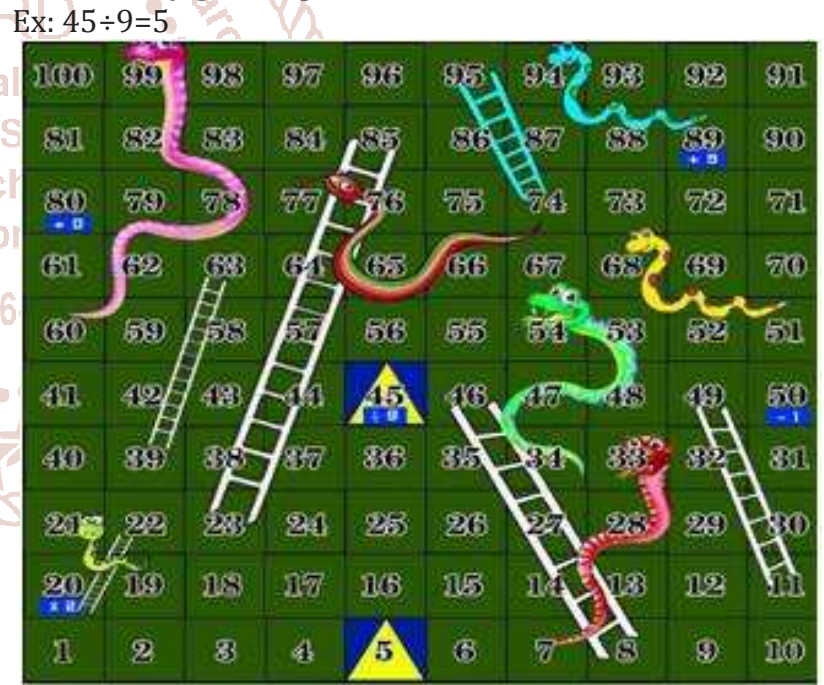

Figure 12

\section{Concept: 17}

Multiplication is the repeated addition i.e from this Snake \& Ladder self-play game, student can prove the multiplication is repeated addition.
Ex: a) 2
$1 * 2=2$
b) $2+2=4$
$2 * 2=4$
c) $2+2+2=6$
$3 * 2=6$
d) $2+2+2+2=8$
$4 * 2=8$

\section{Concept: 18}

Similarly, division is the repeated subtraction.

Ex: a) $12 / 3=412-3=9$

$9-3=6$

$6-3=3$

$3-3=0$

(Subtraction repeated 4 times to get " 0 ") 


\section{Concept: 19}

The concept of Prime numbers exactly 2 factors, 1 \& itself. So we can identify in this game.

Ex:2,3,5,7,11,13,17,19,23,29,31,37,41,43,47,53,5

$9,61,67,71,73,79,83,87,89,97$.

\section{Concept: 20}

Students get acquainted with geometrical Shapes through this game.

\section{CONCLUSION}

Enabling children to learn principal yet tricky subject like Mathematics through similar innovative games eliminates in them, the fear to excel academically and gradually develops cognitive awareness regardless of their individual intelligence quotient. It also helps the teacher impart the concepts effortlessly into the young minds making it a pleasure for both parties involved. Coming up with similar ideas and making them part of curriculum has the power to revolutionize the current education system, helping shape the minds of the future generations hassle-free and superinnovative.

\section{References:}

[1] Coppel, W. A. Number Theory An Introduction to Mathematics.

[2] SK Mangal by Educational psychology.

[3] MFISZ by Number Theory

[4] Elementary Number Theory By David M. burton. 